\title{
A Distance Education Approach to Food Science Training in Sub-Saharan Africa
}

\author{
Mercer, D.G. ${ }^{1}$, Lund, D.B. ${ }^{2}$, Meech, J.S. ${ }^{3}$ \\ (1) Department of Food Science, University of Guelph \\ c/o Kemptville Campus, Kemptville, Ontario, KOE 1X0, Canada. \\ Corresponding Author: E-mail: dmercer@uoguelph.ca \\ (2) North Central Regional Association of Agricultural \\ Experiment Station Directors, Madison, Wisconsin, U.S.A. \\ (3) International Union of Food Science and Technology \\ (IUFoST), Oakville, Ontario, Canada.
}

\section{Abstract:}

A safe, nutritious, and dependable food supply is essential for any society to support and sustain its development. The food processing sector relies upon quality raw food stocks for conversion into affordable marketable products that can reach the consumer through a reliable distribution system. It is the purpose of this paper to outline the development of instructional material for the distance education of food industry workers in sub-Saharan Africa, which is critical at each stage of the food production continuum.

\section{Proposed Training Modules:}

The IUFoST Distance Education Task Force has proposed the development of a set of nine teaching modules in Food Science, Technology, and Nutrition for use in training food industry employees. These modules include:

Food Safety
Dehydration/ Drying
Thermal Processing
Food Freezing
Food Packaging

Food Safety

Dehydration/ Drying

Food Freezing

Food Packaging
Quality Assurance (including HACCP)

Food Laws and Regulations

Shelf-Life of Foods (including food losses)

Practical Human Nutrition

Each training module will be developed to suit the needs of the region and will employ examples of representative materials relevant to the agricultural and agrifood practices of sub-Saharan Africa. Members of the International Academy of Food Science and Technology (IAFoST) would be asked to serve as a resource of expertise for module development and content identification.

The FAO and World Health Organization directives for "Food Safety in Africa" were set out at their October 2005 meeting and reaffirm the need for this type of training and education in agri-food industry. 


\section{Food Drying Pilot Training Module:}

Food drying has been chosen as the subject of a pilot training module. South Africa, Zimbabwe, Botswana, and Kenya have been identified as lead nations for its development and demonstration. A draft course manual on "Food Drying" has been prepared and distributed to representatives from these countries. Topics covered include: drying basics; thermal properties of food materials; calculating the heat to dry a product; drying mechanisms; drying curves; types of dryers; process control in a drying operation; psychrometrics; etc.

The manual is designed to serve as the main information source while students are learning the material and it will serve as a reference after their training has been completed. The material will be modified to address local needs and specialized products as they are identified. Matching the mathematical content of the module with the abilities of the target audience is an initial concern. Cause and effect relationships coupled with detailed relevant case study examples are used throughout the manual.

Ideally, this and subsequent modules would be offered "on-line" in much the same manner as used by North American universities. However, access to the Internet has recently been identified as a potential problem and alternatives such as expanded printed material and videos are being considered.

\section{Next Steps:}

Key contacts in sub-Saharan Africa have been consulted, and several issues have been identified (such as Internet accessibility as mentioned above). Methods of addressing these issues will be investigated in the near future.

Meetings are planned with lead trainers in the four "test" countries to assess the pilot module and to "fine tune"it to suit the needs of their respective target audiences.

Modifications will be made to the course material prior to actual training sessions taking place. Complementary specialized case studies will be developed.

Initial trial training sessions will be conducted in the four "test" and outcomes will be evaluated. Based on these trails, additional modifications to the pilot food drying module can be made as required.

Efforts will be made to secure necessary funding to expand training program if initial pilot training is successful.

\section{Acknowledgement:}

Support of the International Union of Food Science and Technology (IUFoST) is gratefully acknowledged. 